\title{
APPLYING AN ANALOGUE FOR A CONCEPTUAL MODEL FOR THE DEVELOPMENT OF A MEGA NOURISHMENT
}

\author{
Fernanda Achete ${ }^{1,2}$, Arjen Luijendijk $k^{1,2}$
}

This paper discusses the effectiveness of a mega-nourishment project. Mega-nourishment is a new technology for beach nourishment that has recently been developed. It arises as an alternative to beaches where a structural erosion problem is observed and there is the need for continuously nourishments works. A pilot project was implemented near The Hague (The Netherlands) in October 2011, called the Sand Engine [Mulder 2000], however the impacts of such project are widely unknown. From this perspective the study of a natural coastal area that was subjected to similar conditions can generate know how about the impacts of such a project. One of these natural examples is Ameland: one of the Frisian Islands in the Wadden Sea. Ameland experienced large natural nourishment coming from the ebb tidal delta. The nourishment shape and magnitude were in the same order of magnitude of to the Sand Engine project, leading to a comparison point. In the Ameland case this nourishment occurred on 1990`s and on 1993 achieved a similar shape to the Sand Engine pilot project and currently almost all the sediment is already spread. So from the natural case we can assume that the Sand Engine is going to take around 2 decades to spread all the nourished sediment, a special care should be taken in the down-drift coast to avoid early erosion.

Keywords: beach nourishment, data analysis,.

\section{INTRODUCTION}

The Netherlands is classified as a low lying country, since more than $50 \%$ of its territory area lies below mean sea level. The flood protection policy is based on several protection lines. Considering flooding risk from the sea, the primary protection belt is the beach and dune system. After 1953 big storm surge the awareness in coastal protection have been increasing resulting in several political measurements.

In 1990, the Government and the Parliament implemented the Basal Coastline (BCL) policy where they define that the 1990 coastline position should be maintained. To follow this policy it is required that at least $90 \%$ of the Dutch land is situated landward of the BCL, demanding a pro-active approach regarding the chronic erosion problem. In order to archive the standards defined by BCL, a new concept was added in 2000 the dynamic preservation [Mulder 2000]. The aim is to keep the coastal foundation volume, preventing the shore to get steeper and so maintaining the BCL.

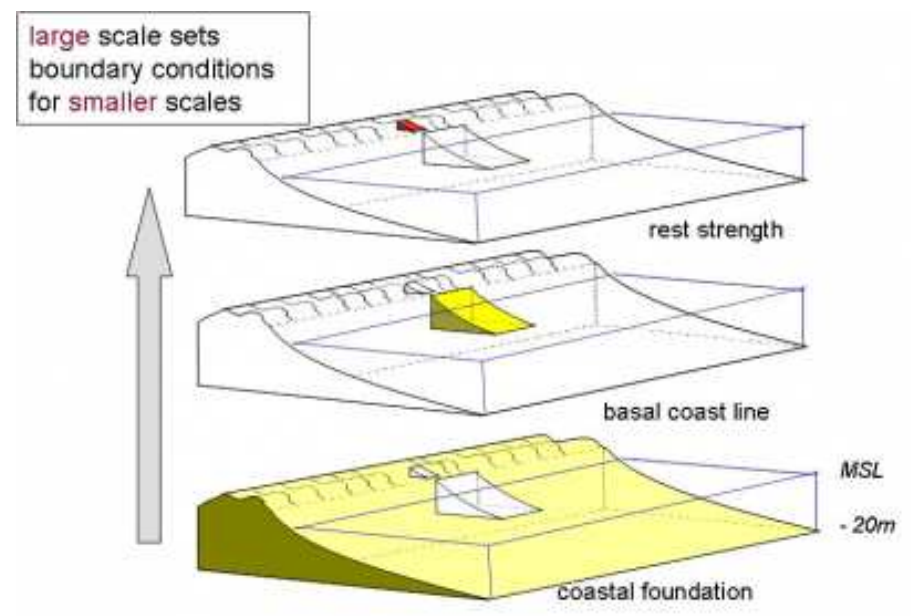

Figure 1: Three different scales in coastal management (source: Mulder et al., 2006)

${ }^{1}$ Coastal Engineering, Delft University of Technology, Postbus 5, Delft, Zuid Holland, 2600AA, The Netherlands 
Within this scenario, the Dutch research program Building with Nature $(\mathrm{BwN})$ aims to developed new basic knowledge, tools and Eco-dynamic alternatives for coastal, delta and estuarine areas. From this expertise, it will be possible to develop new bio-designs where human interventions are reinforced by natural processes. The present work is inserted in the theme 3 of the $\mathrm{BwN}$ program that focuses on the design, realization and evaluation of the Sand Engine (Zand Motor) for the Delfland coast and its contribution to the sustainable development of beaches and dunes.

Nowadays the BCL is maintained by beach nourishments that take place every 4-5 years. The mega-nourishment proposal arises as an alternative to the continuous beach nourishments. These projects consist in performing at once large-scale nourishment and then let nature, currents and wind, redistribute the sediment. In this context, the Sand Engine project was thought as a mega-nourishment pilot project that can be used as a test case for technical and political expertise development, however the morphological behavior of this project is largely unknown and its predictability is uncertain due to a lack in validation data.

One of the Dutch Wadden Sea Island, Ameland, have an attached sand bar (Bornrif) that in a period in the past presented the same shape as the designed to the Sand Engine. In order to have a first idea what could happened to such intervention the Ameland Bornirf morphodynamic was studied and the findings projected in the Sand Engine.

\section{Ameland Bornrif}

The Bornrif is an attached bar at the northwestern edge of the Wadden Sea barrier island, Ameland (Figure 2). Ameland is located in the northern part of Netherlands and together with Terschelling it forms the Amelander inlet. The Bornrif is a dynamic feature influenced by the Ameland estuary dynamics, tides and wave driven currents; however, other aspects as wind, vegetation and bioturbation also play an important role in its development.

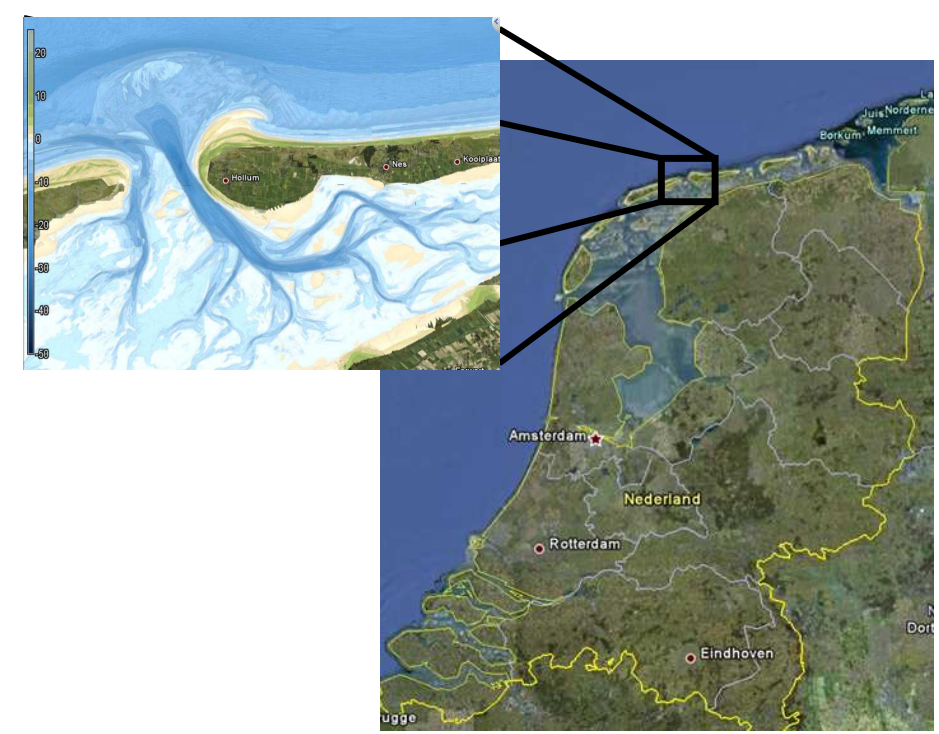

Figure 2: Location of Amelander inlet in relation to The Netherlands

The Bornrif is strongly influenced by the Amelander inlet. The inlet can act as a sediment controller and as convergence region to tidal currents. As sediment input controller two behaviours can be distinguished: it can be considered as a barrier for the wave induced alongshore drift or a source of sediment transported outside from the estuary by tidal asymmetry. These processes result in a nonhomogeneous sediment input to the Bornrif [Stive et al. 2003]. The second point is related to the tidal current modification. The inlet (Borndiep) leads to a local stronger ebb/flood currents due to tidal energy convergence in this area, which can stir more sediment and so easier to be transported.

In this region of the North Sea the tide propagates from west to east with amplitude of approximately $2 \mathrm{~m}$ and $0.7 \mathrm{~m} / \mathrm{s}$ currents [van de Kreeke 1978]. As the fetch in the North Sea is not long 
enough to generate high swells, the big waves observed are storm related. On the Dutch coast, this scenario is reinforced once the mid-latitude atmospheric low pressure travels just on the northern border generating strong northwesterly and westerly wind. This wind field can result in very rough sea states with waves up to $7 \mathrm{~m}$ [Herman et al. 2009]. However, the predominant wave direction is north/northwest/west and most of the time does not exceed $\mathrm{Hs}=2 \mathrm{~m}$ with $\mathrm{T}=5 \mathrm{sec}$ and approximately $11 \%$ of the waves reach the coast as swell against $60 \%$ as storm.

\section{Theoretical Model}

The formation and development of the Bornrif can be explained by the combination of two models: bar evolution in Deltas (De Vriend et al., 1994) and sand spit evolution. As the formation process is not of interest for the Sand Engine understanding the focus is going to be in given in the development process.

In 1993 the Bornrif had a hook shape, the initial design shape of the Sand Engine. In this stage the Bornrif behave similar to a sand spit. Spits are particularly dynamic sand features attached to the edge of a mainland or an island, they are found in sheltered coastal stretches that suddenly change direction. The alongshore sediment transport is extremely important to maintain the spit with its original characteristics. A lack of sediment can cause erosion of the spit and too much sediment input may lead to accretion even creating another spit [Petersen et al. 2008].

Waves play an important role in the spit dynamics; the waves are responsible for shaping the spit. Though the wave depends on the water level, since higher waves can dissipate the energy in the shoal that shelter the spit if the water level is not high enough [Vinther et al. 2004]. Beyond the general sediment transport due to waves induced alongshore current, the waves have other influences as: the spit width is proportional to the surf zone; the curvature radius depends on the wave height and the overwash processes accelerate the spit migration shoreward [Dan et al. 2009].

Even if there is a common evolution history, the spits can be also be classified into 3 categories, depending on the angle in relation to the up-drift coast(Error! Reference source not found.)[Petersen et al. 2008]: small angle, the spit will erode (E1), too big there is accretion (E2), the perfect spit is going to develop and grow in length (E3).

The Bornrif is comparable to E2 (Figure 3), where the angle between the wave direction and the Bornrif is so low that the transport capacity is also too low quickly accreting the spit that merges with the mainland. It is worth to note that in the Bornrif case, there is not a proper up-drift coast, and the sediment supply comes from the bypass trough the ebb tidal delta and from the Ameland estuary.

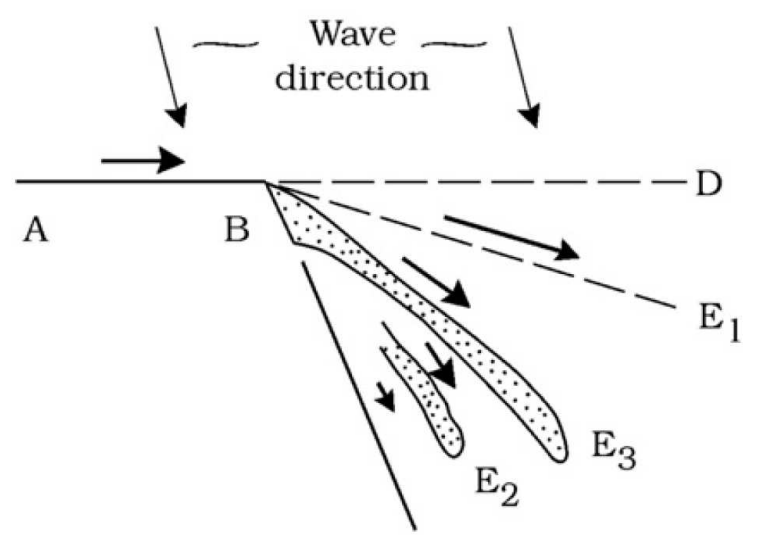

Figure 3:Spit orientation in relation a hard point B (source: Petersen et al., 2008)

\section{Data Profile Analysis}

The Dutch Wadden Sea has been monitored for many years, however since 1993, with the SBWproject (Sterkte en Belastingen Waterkeringen); this effort has increased in time and space. The data used in the present work is mostly described in de Fockert [2008], though data from subsequent years (from 2006 to 2009) was added. 
The two main bathymetric databases used were the JARKUS ('JAaRlijkse Kustlodingen', Ruessink, 1998) and the Vaklodingen. The JARKUS is one of the biggest beach profile dataset in the world, dating from 1963 of annual soundings from the dunes reaching until 16 meters depth crossshore. The Vaklodingen dataset is the standard Rijkswaterstaat (RWS) monitoring soundings, performed every three years for delta environments. It is stored in a resolution of $20 \times 20$ meters and reaches 35 meters depth since 1987 [Elias 2007]. Both data sets are based on the NAP (Normal Amsterdam's Peil, close to the means sea water level) and are performed during summer, aiming observe inter-annual and not the seasonal variability.

From this data set it is possible to describe the Bornrif evolution analyzing the measured profiles (Figure 4). The profiles gives an idea of how long does the propagation takes and how steep the profiles become, as well how the impact on the coast line is.

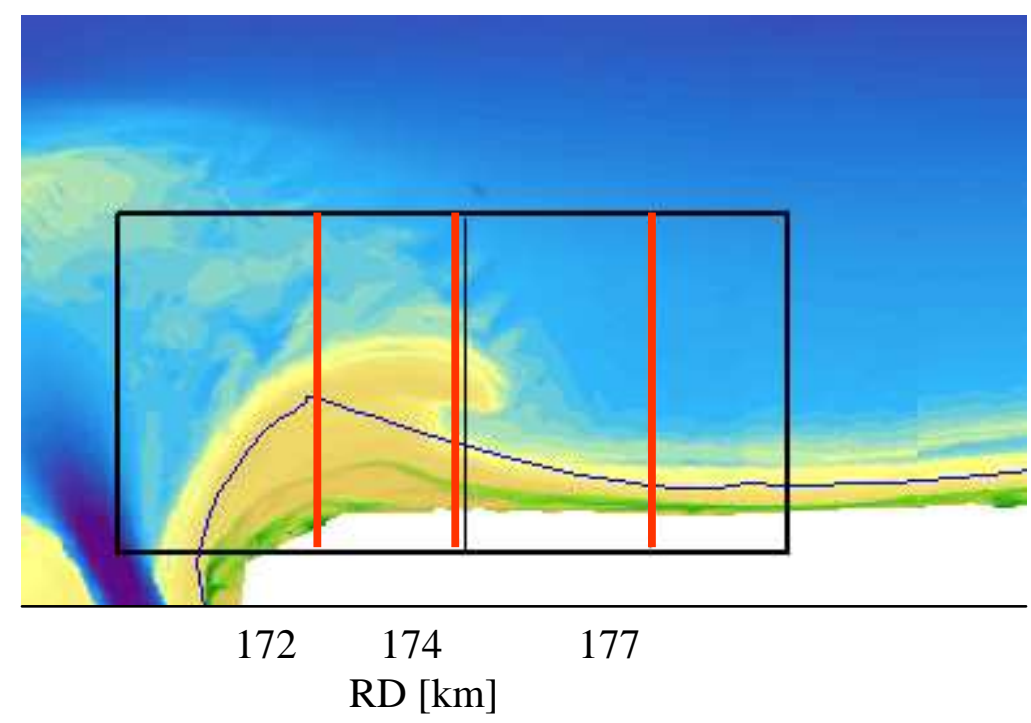

Figure 4: Profile locations

Profile A is representative of the Bornrif edge, where severe erosion process takes place. The erosion in the shore-face, between 0 and 6 meters depth, is order of $750 \mathrm{~m}$ in 15 years. From the eroded sediment, part is exported downdrift and part of it is transported onshore nourishing the dune foot. In profile $\mathrm{A}$, it is possible to visualize submerged sandbars and a big bar coming from the ebb-tidal delta (year 2008), that probably is the formation of the new bypass bar (Figure 5).

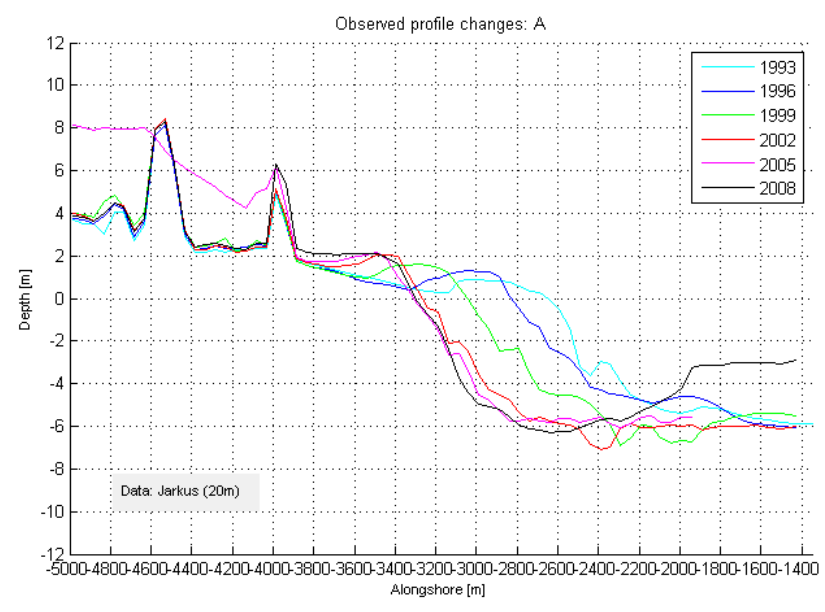

Figure 5: Cross-shore section A, on km 172, over the years 
The profile B was chosen in order track the spit tip evolution. It is possible to distinguish a 4 meter height emerged bar approaching the main land; it is the sand spit. The spit reaches the coast around 1996, when a channel linking the inside tidal bay to the open sea is formed. The complete merge with the mainland arise by 2000 when the channel is closed (Figure 6).

In $B$, the erosion takes place in deeper part of the profile, around -4 and $-6 \mathrm{~m}$ that get steeper over the years. As in profile A, it is possible to observe sand bars other then the spit.

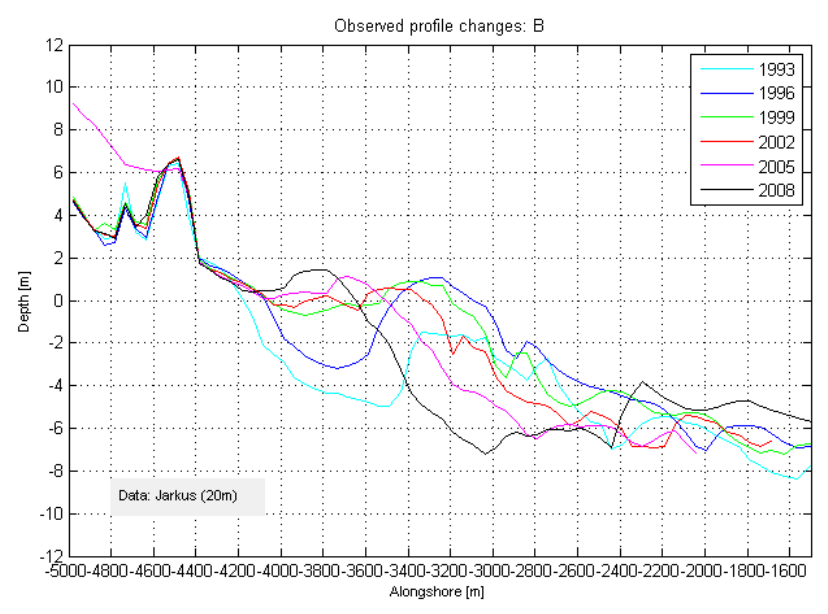

Figure 6: Cross-shore section B, on km 174, over the years

The last profile is $\mathrm{C}$, it represents the eastern sheltered part of the domain. Here the main process is deposition of sediment coming from the Bornrif; however, some erosion event can be distinguished. In average, the entire profile has advanced around 200m seawards with a higher rate from 1996 to 2000. Around the year 1997 the sand bars start to reach the area where the profile $\mathrm{C}$ is located, one of the reasons to the higher deposition rate. It is important to reinforce that the accretion state is the profile tendency that can varies from year to year (Figure 7).

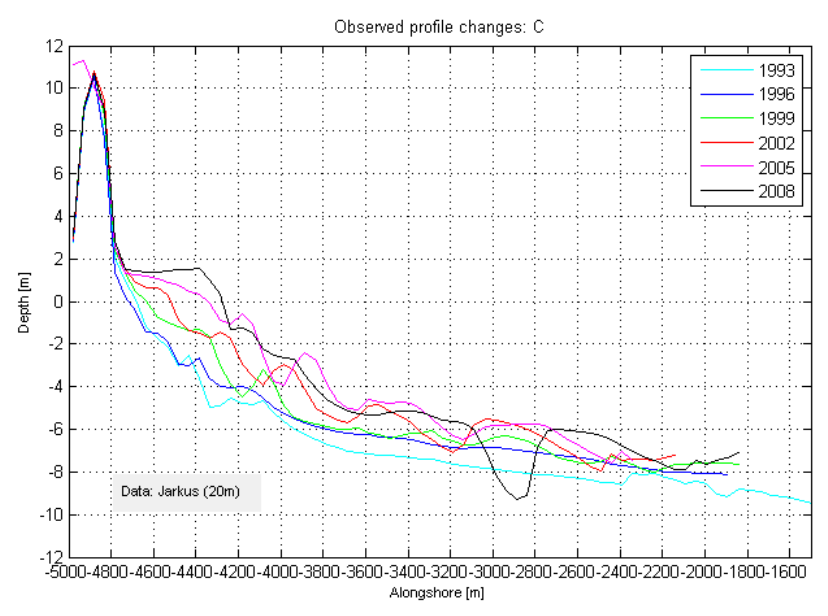

Figure 7: Cross-shore section C, on km 176, over the years

Concerning the dune erosion its analysis was performed separately, since the erosion and accretion observed on dunes are in order of 10 to 50 meters so, one order of magnitude lower than in the profile shore-face. For the profile A, was observed in 2005 a 15 -meter retreat in the upper part of the dune (form 4 to 6). On the other hand, in profile B observed 80 meters retreat of the dune foot around 1996 due to the inlet channel formation and meandering, the channel meanders advance shoreward creating an erosive region. In 2000 with the closure of the inlet, the erosion stops; and the dune foot starts to recover from 2005. In profile $\mathrm{C}$ no substantial (more than 5 meters) dune erosion was observed. 


\section{Conceptual Model}

In this section is presented the Bornrif morphodynamics state of art, derived from the literature review and the data analysis. The conceptual model shows and describes, for the time interval from 1993 to 2003, which are the main features and processes related to the Bornrif development.

The conceptual model shows and describes, for the time interval from 1993 to 2003, which are the main features and processes related to the Bornrif development. Four stages (1, 2, 3 and 4, explained below) were distinguished according to the Bornrif shape and erosion/accretion regions. The year of 1993 was chosen as start point to the analysis since is the most similar shape to the Sand Engine design.

Before beginning with the stages characterization, it is important to explain the main driving force of the Bornrif dynamics, the waves. The principal wave direction is N/NW so when the wave front reaches the Bornrif west outer edge creates a divergence area (Figure $8 \mathrm{i}$ ). The wave action is reinforced (depleted) by the vertical tidal action, which changes the mean water level letting more (less) wave penetration.

Having the above mentioned process in mind the stage 1 starts in 1993 and goes until 1995, is the stages where the wave divergence in the outer edge is more intense. Due to the wave divergence, the northwestern Bornrif coast is intensively eroded (B), in an average rate of $1 \mathrm{~m} / \mathrm{y}$. From the total eroded sediment, less than $15 \%$, is transported southwards and the rest $85 \%$ is transported eastward [Chenug et al. 2007]. The southward branch is going to accrete at the western Amelander coast (A) and the eastward is going to be deposited in the hook formation, which is growing southeastwards (C) (Figure 8 i).

Still in phase 1, the eastern coast behaves as an erosive coast (D). One reason for the erosion is that the Bornrif traps most of the sediment that suppose to reach the eastern coast; the attached bar act as a big groin for the alongshore current.

Stage 2 (1996-1997), is similar to stage one concern the main forcing and accretion/erosion patterns. However, the spit reaches a point where a clear narrow tidal channel is shaped; it is the inlet for the tidal lagoon formed landward of the spit (E) (Figure 8 ii) [Cleveringa, 2005].

The stage 2 develops into stage 3 (1998-1999) as the channel increases in length due to the sediment input. As the channel gets longer, it becomes less efficient, leading to meandering (F). This meandering process erodes the shoreline reaching the dune foot. In stage 3 the Bornrif is smoother, less prominent, consequently the erosion/accretion process is damped out too; this trend is the result of the Bornrif coastline achieving an equilibrium state in relation to the wave direction therefore the sediment transport capacity decreases. The third aspect of stage 3 is the sand wave penetration, as the Bornrif is smoothed; it lets more space to the sand waves propagate inside the study domain (Figure 8 iii).

The spit merging with the mainland characterizes stage 4 (2000-2003). The loss of hydraulic head due to siltation leads to inlet closure. Afterwards, probably due to storms events, a new channel is opened in the north coast; as a dynamic region, this channel is constantly being closed and opened again, in a weaker point of the Bornrif coastline (Figure 8 iv).

The difference between the selected start point, 1993 and the final one, 2003 is presented in (Figure $8 \mathrm{v})$. 


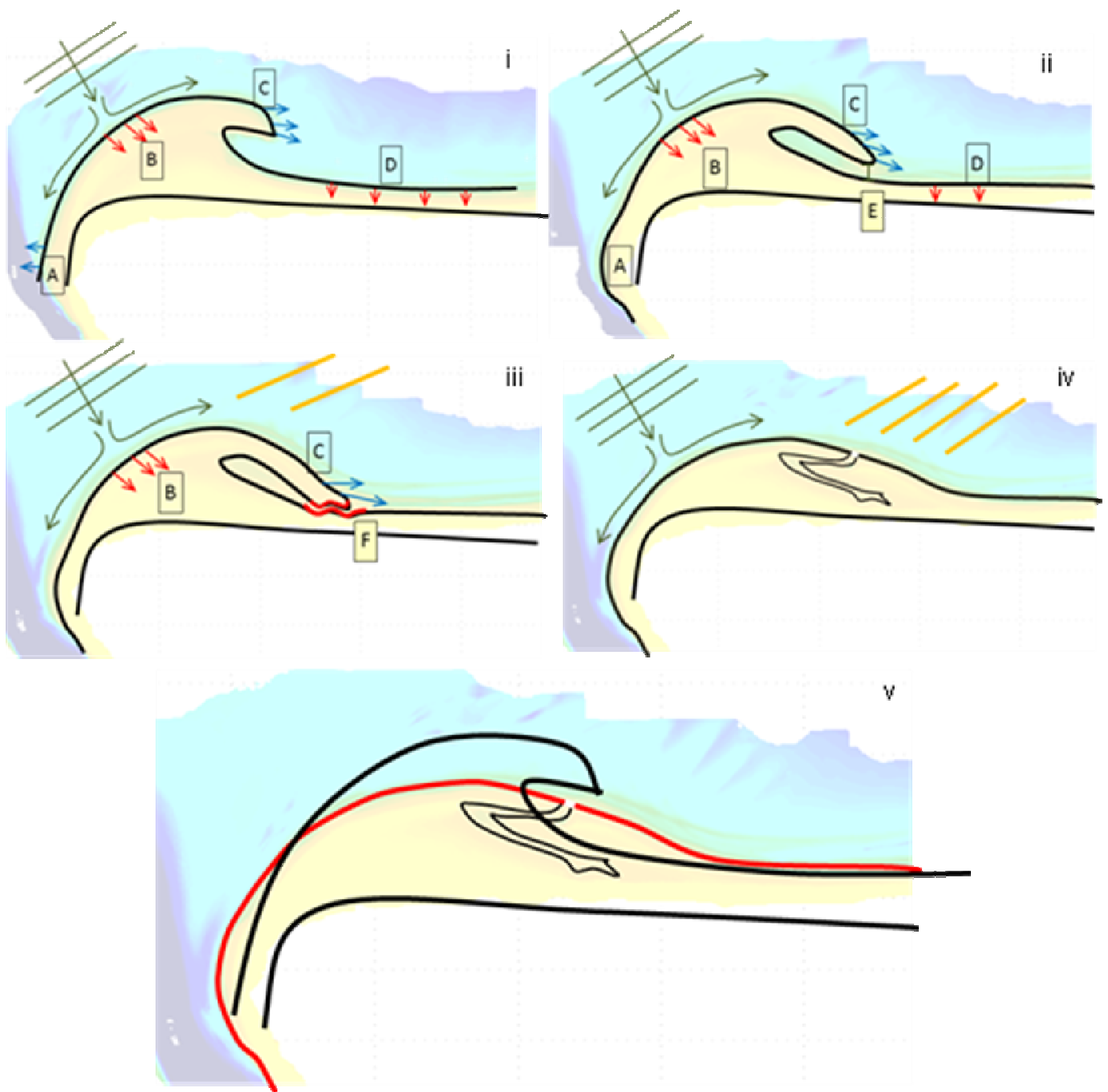

Figure 8: Schematic draw for i) phase 1, ii) phase 2 iii) phase 3 and iv) phase 4. Red arrows shows erosion and blue accretion, the gray arrows show incident wave and the divergence point, the yellow lines represent the sand waves. v) Schematic representation of the coastline in 1993, in black, and 2003 in red.

\section{Sand Wave x Plunging Wave}

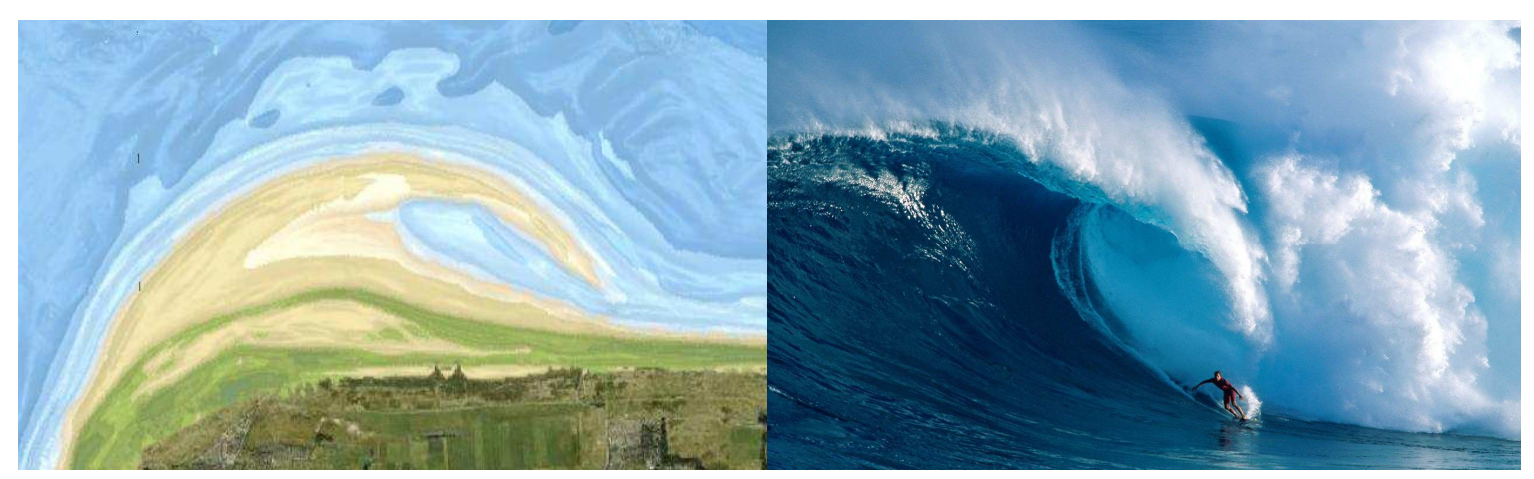

Figure 9: Morphological similarity between the Bornrif (left) and a plunging wave (right). 
Observing the Bornrif development throughout the time, a clear similarity with plunging wave arises. Nevertheless, the similarity is not restricted to the general shape but also some wave characteristics are present in the Bornrif, the wave of sand.

Mead and Black [2001], developed a classification system for the plunging wave intensity, where the vortex characteristics are investigated (Figure 10). In their classification, the ration between the vortex length and the width is the parameter descriptive term. They found that as lower the vortex ratio more intense is the breaking; from this system, the Bornrif can be comparable to a medium intensity breaking, presenting vortex ratio of 3.2.

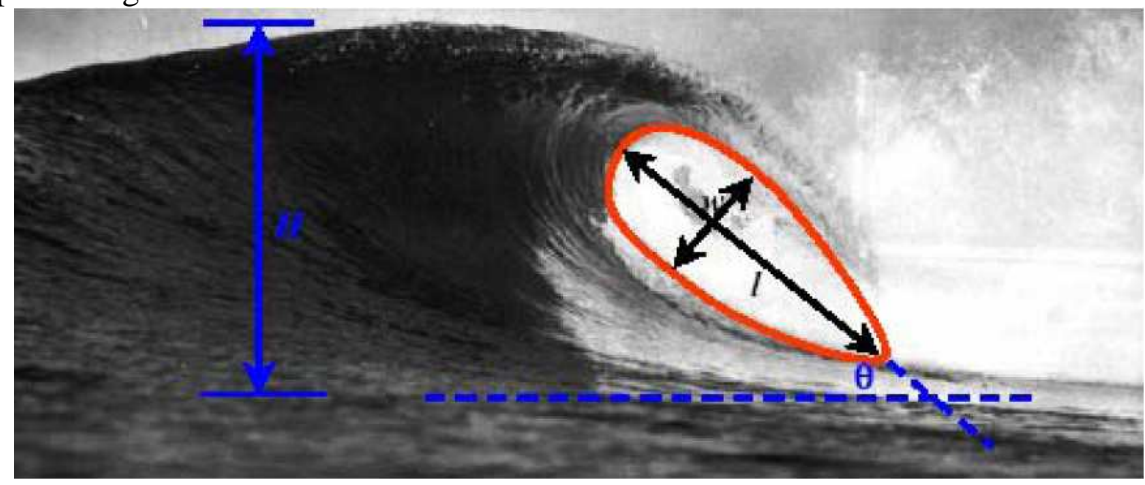

Figure 10: Curve fitting applied to the forward face of a crest parallel wave. Used to calculate the vortex length (I), width (w) and angle ( $\theta)$. (source: Mead and Black, 2001)

\section{Projection of findings on the Sand Engine Delfland}

This section discusses which conclusions from the Bornrif can be extended to the Sand Engine pilot project. The morphological development in general is expected to follow the same trend taking into consideration the findings in this study. Several patterns can be highlighted from the comparison (Figure 11):

- The hooks develops in a similar way, as a plunging wave. The tip of the hook heads towards the coast forming a bay. The time for the spit to reach the coast the coast is around 3 years.

- As the spit approaches the mainland, it forms a coastal lagoon; the connection with the open sea is maintained via a channel. The channel extends in length due to the accretion in the spit, with sediment coming from the Bornrif.

- The shape of the lagoon can be assessed applying the vortex ratio. It is expected that the ratio be between 2 and 3.4, most probably closer to 3.4 as the hook length is big.

- After the merging with the mainland, the resulting emerged and submerged shape reaches equilibrium with the wave directions. In this phase the morphological changes slow down. Therefore, the period to spread the sediment after that is almost 2 times the period taken to the spit reach the coast (observed in data and in the Bornrif simulation).

- Comparing the western edge behaviour it is necessary to keep in mind that some main differences between the Bornrif and the Sand Engine Delfland. The edge of the Bornrif ends is part of the estuary inlet and in the Sand Engine case, is located in a continuous sandy coastline.

- However, in both cases the western edge is the side where the most waves reach the coast, so a divergence point appears resulting in transportation of sediment southwards as eastwards. In the Bornrif case, the sediment transported southwards is carried through the Borndiep but in the Sand Engine, a recirculation cell is formed spreading sediment in both north and south directions.

- Another remarkable point concerning the estuary is the presence of an ebb-tidal delta in the Bornrif case and not in the Sand Engine. As discussed in the report the ebb-tidal delta influences the wave breaking and the wave induced current. The modification of these two forces can lead to different evolution; mostly on the tip propagating behavior observed in the Bornrif, the Sand Engine can show a more diffusive pattern (Figure 11, top line).

- The ebb-tidal delta releases cyclic sand waves that propagates in the Bornrif direction, and will not be observed in the Sand Engine. This bars can influence the morphodynamics by nourishing the Bornrif, in this case the period of the Sand Engine spreading can be smaller than the observed for the Bornrif. On the other hand this bar can only provide the amount of sediment that is lost to the 
estuary, keeping the equilibrium, in this way does not have any influence in the findings for the Sand Engine.
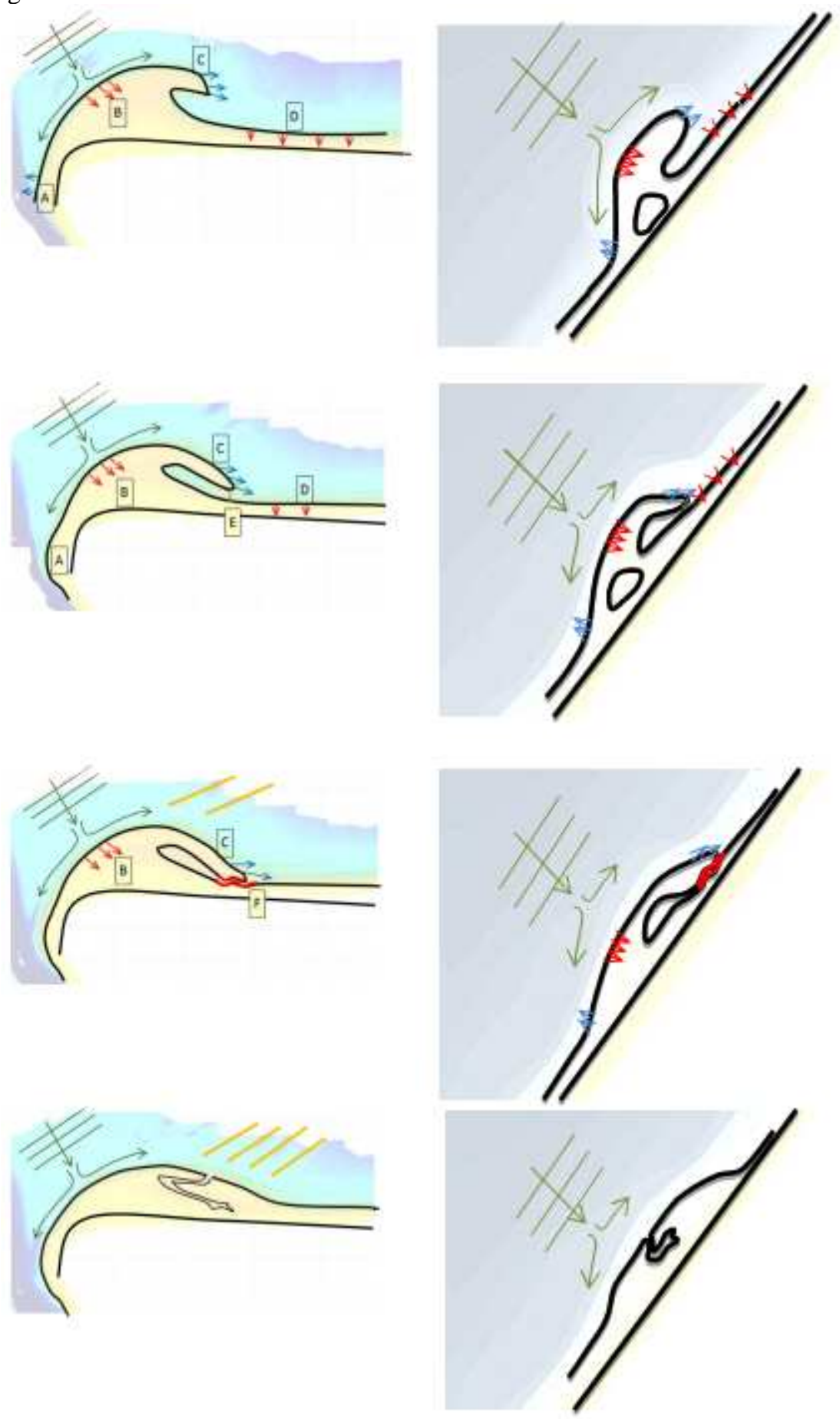

Figure 11: Sketch of the conceptual model of the Bornrif left and the Sand Engine right. Red arrows menas erosion and blue accretion, the green represent the waves and waves induced current. 


\section{ACKNOWLEDGMENTS}

Deltares, where the work was delveloped. Erasmus Mundus EU.

\section{REFERENCES}

De Vriend, H.J., J. Zyserman, J. Nicholson, J.A. Roelvink, P. Pechon, and H.N. Southgate. 1993. Medium-term 2DH coastal area modeling, Coastal Engineering, 21, 193-224.

Lesser, G. R., J. A. Roelvink, J. A. T. M. van Kester, et al. (2004). "Development and validation of a three-dimensional morphological model." Coastal Engineering 51(8-9): 883-915.

Roelvink, J. A. (2006). "Coastal morphodynamic evolution techniques." Coastal Engineering 53(2-3): 277-287.

Roelvink, J. A., L. C. van Rijn and R. C. Steijn (1999). Morphodynamic simulations of the tidal inlet "Zeegat van Ameland".

Stive, M. J. F., Z. B. Wang and V. C. Lakhan (2003). Chapter 13 Morphodynamic modeling of tidal basins and coastal inlets. Elsevier Oceanography Series, Elsevier. Volume 67: 367-392.

van de Kreeke, J. (1978). "Mass transport in a coastal channel, Marco River, Florida." Estuarine and Coastal Marine Science 7(3): 203-214.

van de Kreeke, J. (2006). "An aggregate model for the adaptation of the morphology and sand bypassing after basin reduction of the Frisian Inlet." Coastal Engineering 53(2-3): 255-263.

Dan, S., M. J. F. Stive, D.-J. R. Walstra, et al. (2009). "Wave climate, coastal sediment budget and shoreline changes for the Danube Delta." Marine Geology 262(1-4): 39-49.

Fockert, A. d. (2008). Impact of Relative sea Level Rise on the Amelander Inlet Morphology. Coastal Engineering. Delft, TU Delft. Master in Science.

Vinther, N., J. r. Nielsen and T. Aagaard (2004). "Cyclic Sand Bar Migration on a Spit-platform in the Danish Wadden Seaâ€”Spit-platform Morphology Related to Variations in Water Level." Journal of Coastal Research: 672-679.

Petersen, D., R. Deigaard and J. Fredsøe (2008). "Modelling the morphology of sandy spits." Coastal Engineering 55(7-8): 671-684.

Elias, E. v. K., M.; Tonnon, P.K. and Wang, Z.B. (2007). Sediment budget analysis and testing hypoteses for the Dutch coastal system. Advance in Hydro-Science and Engineering. Den Haag.

Cleveringa, J., C. G. Israel and D. W. Dunsbergen (2005). De westkust van Ameland. Den Haag, The Netherlands, Rijkwaterstaat: 74.

Mead, S. a. B., K. (2001). "Predicting the Breaking Intensity of Surfing Waves." Journal of Coastal Research SI 29(SI 29): 51-65.

Mulder, J. P. M. (2000). Zandverliezen in het Nederlandse kustsysteem, Rijkswaterstaat, RIZK.

Nicholas, C. K. (2000). "Reservoir Model of Ebb-Tidal Shoal Evolution and Sand Bypassing." Journal of Waterway, Port, Coastal, and Ocean Engineering 126(6): 305-313. 